\title{
RESEARCH
}

Open Access

\section{Childhood Langerhans cell histiocytosis with severe lung involvement: a nationwide cohort study}

Solenne Le Louet ${ }^{1 *}$ (D), Mohamed-Aziz Barkaoui ${ }^{1}$, Jean Miron', Claire Galambrun², Nathalie Aladjidi , Pascal Chastagner ${ }^{4}$, Kamila Kebaili ${ }^{5}$, Corinne Armari-Alla ${ }^{6}$, Anne Lambilliotte ${ }^{7}$, Julien Lejeune ${ }^{8}$, Despina Moshous ${ }^{9,10}$, Valeria Della Valle ${ }^{11}$, Chiara Sileo ${ }^{11}$, Hubert Ducou Le Pointe ${ }^{11}$, Jean-François Chateil ${ }^{12}$, Sylvain Renolleau ${ }^{13}$,

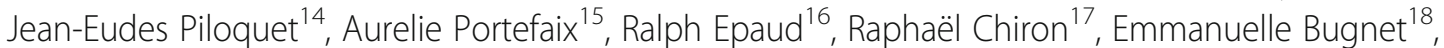
Gwenaël Lorillon $^{18}$, Abdelatif Tazi ${ }^{18,19}$, Jean-François Emile ${ }^{20}$, Jean Donadieu ${ }^{1,21}$ and Sébastien Héritier ${ }^{1,20,21}$

\begin{abstract}
Background: Lung involvement in childhood Langerhans cell histiocytosis $(\mathrm{LCH})$ is infrequent and rarely life threatening, but occasionally, severe presentations are observed.
\end{abstract}

Methods: Among 1482 children (< 15 years) registered in the French LCH registry (1994-2018), 111 (7.4\%) had lung involvement. This retrospective study included data for 17 (1.1\%) patients that required one or more intensive care unit (ICU) admissions for respiratory failure.

Results: The median age was 1.3 years at the first ICU hospitalization. Of the 17 patients, 14 presented with lung involvement at the LCH diagnosis, and 7 patients (41\%) had concomitant involvement of risk-organ (hematologic, spleen, or liver). Thirty-five ICU hospitalizations were analysed. Among these, 22 (63\%) were secondary to a pneumothorax, 5 (14\%) were associated with important cystic lesions without pneumothorax, and 8 (23\%) included a diffuse micronodular lung infiltration in the context of multisystem disease.

First-line vinblastine-corticosteroid combination therapy was administered to 16 patients; 12 patients required a second-line therapy (cladribine: $n=7$; etoposide-aracytine: $n=3$; targeted therapy $n=2$ ). A total of 6 children $(35 \%)$ died (repeated pneumothorax: $n=3$; diffuse micronodular lung infiltration in the context of multisystem disease: $n=2$; following lung transplantation: $n=1$ ). For survivors, the median follow-up after ICU was 11.2 years. Among these, 9 patients remain asymptomatic despite abnormal chest imaging.

Conclusions: Severe lung involvement is unusual in childhood LCH, but it is associated with high mortality. Treatment guidelines should be improved for this group of patients: viral infection prophylaxis and early administration of a new LCH therapy, such as targeted therapy.

Keywords: Childhood, Pulmonary, Langerhans cell histiocytosis, Targeted therapy, Intensive care, Severe

\footnotetext{
* Correspondence: solennelelouet@gmail.com

${ }^{1}$ French Reference Center for Langerhans Cell Histiocytosis, Trousseau

Hospital, 26 avenue du Dr Netter, 75012 Paris, France

Full list of author information is available at the end of the article
}

\section{$\triangle B M C$}

(c) The Author(s). 2020 Open Access This article is licensed under a Creative Commons Attribution 4.0 International License, which permits use, sharing, adaptation, distribution and reproduction in any medium or format, as long as you give appropriate credit to the original author(s) and the source, provide a link to the Creative Commons licence, and indicate if changes were made. The images or other third party material in this article are included in the article's Creative Commons licence, unless indicated otherwise in a credit line to the material. If material is not included in the article's Creative Commons licence and your intended use is not permitted by statutory regulation or exceeds the permitted use, you will need to obtain permission directly from the copyright holder. To view a copy of this licence, visit http://creativecommons.org/licenses/by/4.0/ The Creative Commons Public Domain Dedication waiver (http://creativecommons.org/publicdomain/zero/1.0/) applies to the data made available in this article, unless otherwise stated in a credit line to the data. 


\section{Background}

Langerhans cell histiocytosis ( $\mathrm{LCH})$ is a rare disease that occurs more frequently in children than in adults. $\mathrm{LCH}$ has extremely variable clinical manifestations $[1,2]$. It is a clonal disorder characterized by an accumulation of pathological CD1a + CD207+ histiocytes, affecting nearly all organ systems, and thus, leading to a myriad of clinical manifestations. The lungs are involved in approximately $10 \%$ of children with $\mathrm{LCH}$. Somatic mutations are typically found in a proto-oncogene in the MAPKinase pathway (mostly $B R A F^{\mathrm{V} 600 \mathrm{E}}$ ) [3, 4]. For each patient, the extension of the disease is established based on the classification of the international medical society of histiocytic disorders (Histiocyte Society). This classification considers affected organs number, lung involvement and the risk of organ involvement ( $\mathrm{RO}+$ ), defined as the liver, spleen, and haematological system. Currently, the lung is no longer considered an RO [5-7]. Pulmonary involvement in LCH (PLCH), is typically observed in two distinct clinical presentations in children $[2,7,8]$. In one presentation, lung involvement in young children is mostly associated with a multisystemic disease (MS) with RO involvement. It remains in the nodular stage, seldom presents with pneumothorax, and it can be cured with a systemic disease treatment, without sequelae. In the other presentation, lung $\mathrm{LCH}$ disease typically occurs in adolescents and young adults with an insidious onset. Lung damage develops insidiously, and the disease might not be revealed until the pneumothorax stage $[9,10]$.

Importantly, PLCH pathogenesis is different between childhood and adulthood, because over $95 \%$ of affected adults are cigarette smokers [11]. Thus, PLCH is mainly described in adults with a peak frequency at ages 20-40 years. On the other hand, lung involvement in childhood LCH is less often described, due to much lower occurrence [7, 12-14]. In young adults, computed tomography (CT) scans typically show nodules and cysts, predominantly in the upper and middle lung fields $[11,15]$. Adult PLCH histology is characterized by focal CD1a-positive cells, often organized into granulomas, that infiltrate and destroy distal bronchioles, resulting in cyst formation and pulmonary tissue destruction [9]. The evolution of $\mathrm{PLCH}$ in young adults ranges from self-regression, upon discontinuing tobacco consumption, to severe respiratory failure [16]. Secondary pulmonary hypertension can shorten life expectancy. Additionally, lung disease can be life-threatening and might require lung or heart-lung transplantation $[9,17]$.

Exceptionally, within children, even at a young age, $\mathrm{LCH}$ may present as severe lung damage, as typically observed in young adults. Management of these exceptional cases of young children with very severe lung disease is challenging; only few case reports have been published [7, 18-27]. Certain described children required management in an intensive care unit (ICU) for respiratory decompensation. Although most patients described remained alive at the publication date, long-term prognosis has remained unclear, and optimal management has not been defined.

Due to recent progress broadening $\mathrm{LCH}$ pathogenesis molecular understanding [28], $\mathrm{LCH}$ has been associated with a very low mortality rate. Indeed, patients with $B R A F^{\mathrm{V} 600 \mathrm{E}} \mathrm{mu}-$ tations and MS RO+ LCH historically had the worst prognosis. Currently, these patients typically respond to BRAF inhibitors [29], greatly improving their survival [13].

The present study aimed to provide data on the rare cases of very severe PLCH in childhood to facilitate future treatment strategies development.

\section{Methods}

\section{Patients and ethics statement}

This multicentre, retrospective observational study included patients under 15 years old with $\mathrm{PLCH}$ that required at least one ICU hospitalization for respiratory decompensation between 1994 and 2018. All children were registered in French LCH registry [13]. Patients in the registry had to fulfill LCH diagnostic criteria [30]. Additionally their parents had to provide informed consent (Commission Nationale d'Informatique et des Libertés number in France: 909027) for a prospective follow-up. This procedure complied with the Declaration of Helsinki. The registry file was managed by the French reference centre for histiocytosis, located at the Armand Trousseau hospital (Paris, France). Data were recorded prospectively in the registry, starting at patient enrolment. For all eligible patients in the registry files, we collected LCH presentation data, clinical characteristics, outcome, therapeutics, and management during all ICU hospitalizations. When data was missing, we submitted a request for information to the department responsible for the patient.

\section{Definitions}

Disease extension was defined according to international criteria. Single-system (SS) LCH involves only one organ affected. Multisystem (MS) LCH involves two or more organs/systems, and "risk organs" $(\mathrm{RO}+)$ included the haematopoietic system, liver and spleen. Lung involvement was defined as a confirmed LCH diagnosis with symptomatic (dyspnoea, cough, cyanosis) or asymptomatic lung disease and characteristic pulmonary findings on a chest X-ray or computed tomography scan. These characteristic findings included symmetric, bilateral reticulonodular opacities, more or less associated with cysts, and a combination of nodules and cysts on a CT scan. Complete pneumothorax was defined as an entire lung collapses on the affected side. Pneumothorax was bilateral if both the right and the left sides of the lung are concerned.To quantify dyspnoea, we retrospectively attributed scores, based on the New York Heart Association (NYHA) functional classification: I, no limitation of physical activity; II, slight limitations in physical 
activity, but ordinary physical activity resulted in fatigue, palpitation, and dyspnoea; III, marked limitations in physical activity, and less than ordinary activity caused fatigue, palpitation, or dyspnoea, but the patient was comfortable at rest; IV, unable to carry on any physical activity without discomfort, and the patient experienced symptoms at rest.

Biopsy date is considered $\mathrm{LCH}$ diagnosis date. When a biopsy was available for a molecular study, the $B R A F^{\mathrm{V} 600 \mathrm{E}}$ mutation was investigated, as previously described [4], and in some cases, other MAPK mutations were investigated. Treatment efficacy was evaluated according to the classification used by the Histiocyte Society [31].

The lung CT score was developed by our group to analyse distribution and extension of nodular and cystic lung lesions and to assess treatment therapeutic impact (Della Valle et al., under review). This scoring system evaluated nodules and cysts separately [15]: the chest was divided into 6 fields (upper, middle, and lower fields in the left and right lungs). Each field was scored as follows: $0=$ no lesion, $1=$ lesions involving up to $25 \%$ of the parenchyma, $2=$ lesions involving $25-50 \%$ of the parenchyma, $3=$ lesions involving $50-75 \%$ of the parenchyma, and $4=$ lesions involving more than $75 \%$ of the parenchyma. The maximum score was 24 for extensions in both nodules and cysts.

\section{Statistical analyses}

Statistical analyses were performed with Stata $^{\circ} 13$ software. The cut-off date for these analyses was June 30, 2019. Survival analyses included the interval between pulmonary LCH diagnosis and death. In these analyses, patients were censored at the date of the last examination or death. Survival rates were estimated with the Kaplan-Meier method.

\section{Results}

\section{Demographic and clinical data}

Among 1482 children under 15 years old that were followed in the French LCH registry between 1994 and 2018, 111 patients $(7.4 \%)$ had a lung involvement, whereof 17 (1.1\%) had severe lung involvement and required hospitalization in an ICU (Table 1). Comparison of PLCH children with and without history of ICU admissions for respiratory failure is showed in Supplemental Table 1. Among the 17 patients, 7 (41\%) had RO involvement (liver: $n=7$; haematologic: $n=4$; and spleen: $n=5$ ) and were classified as MS RO+ LCH; 3 had isolated lung involvement (Lung+ SS LCH); and 7 had Lung+ MS RO-, with other organ involvement (skin: $n=5$; bone: $n=2$; pituitary: $n=2$; lymph node: $n=2$; tumorous central nervous system: $n=1$ ). The median age of all 17 patients was 1.2 years (range, 2 days to 13.7 years) at the initial $\mathrm{LCH}$ diagnosis. The median ages at the $\mathrm{LCH}$ diagnosis
Table 1 Characteristics of 17 children with LCH with severe lung involvement

\begin{tabular}{ll}
\hline Characteristics & $n=17$ (\% of cases) \\
\hline Male & $8(47)$ \\
Female & $9(53)$ \\
Age at diagnosis (median) & 1.2 y \\
$<3$ years & $12(71)$ \\
$>3$ years & $5(29)$ \\
Lung+ SS LCH & $3(18)$ \\
Lung MS RO- LCH & $7(41)$ \\
Lung MS RO+ LCH & $7(41)$ \\
Bone involvement & $6(35)$ \\
Skin involvement & $11(65)$ \\
Pituitary involvement & $4(24)$ \\
Tumorous central nervous system & $2(12)$ \\
Liver involvement & $7(41)$ \\
- including sclerosing cholangitis & 1 \\
Hematologic involvement & $4(27)$ \\
Spleen involvement & $5(29)$ \\
Lung involvement & $17(100)$ \\
Lymph node involvement & $6(35)$ \\
First line VLB-steroid regimen & $16(94)$ \\
Second-line therapy & $12(71)$ \\
2 CDA & $7(41)$ \\
VP-16 Ara-C & $3(18)$ \\
Targeted therapy & $2(12)$ \\
LCH reactivation & $8(47)$ \\
BRAF & $4 / 11$ \\
MAPooE mutation (mutated/investigated cases) & 1 \\
Abbreviations: DAs Disean & \\
\hline
\end{tabular}

Abbreviations: DAS Disease Activity Score, $L C H$ Langerhans cell histiocytosis, PLCH Pulmonary LCH, VLB vinblastine, VP16 Ara-C Etoposide-Cytarabine, 2CDA Cladribine, $R O$ Risk organs involved, MS Multi-System, SS Single-System

were 0.7 years for patients with $\mathrm{MS} \mathrm{RO}+, 1.2$ years for patients with Lung+ MS RO- with other organ involvement; and 5.0 years for patients with Lung+ SS. Lung involvement was diagnosed at the initial $\mathrm{LCH}$ diagnosis in $14 \mathrm{pa}-$ tients, and 3 children developed lung involvement at $\mathrm{LCH}$ reactivation. The latter 3 patients had an initial normal chest X-ray at diagnosis; the lung involvement was diagnosed at a median delay of 2.4 years (range, 0.6 to 2.4) after the initial $\mathrm{LCH}$ diagnosis. At the PLCH diagnosis, 3 patients had no respiratory symptoms, 14 had dyspnoea (NYHA dyspnoea score II: $n=2$; NYHA dyspnoea score IV: $n=12$ ), and 11 had pneumothorax. The available CT scans acquired at PLCH diagnosis are shown in Fig. 1. $\mathrm{LCH}$ biopsy samples were available for 11 patients. A molecular study showed that 4 patients had the $B R A F^{\mathrm{V} 600 \mathrm{E}}$ mutation, and one patient had a MAP2K1 ${ }^{\mathrm{F} 53 \text {-Q58del }}$ mutation. 


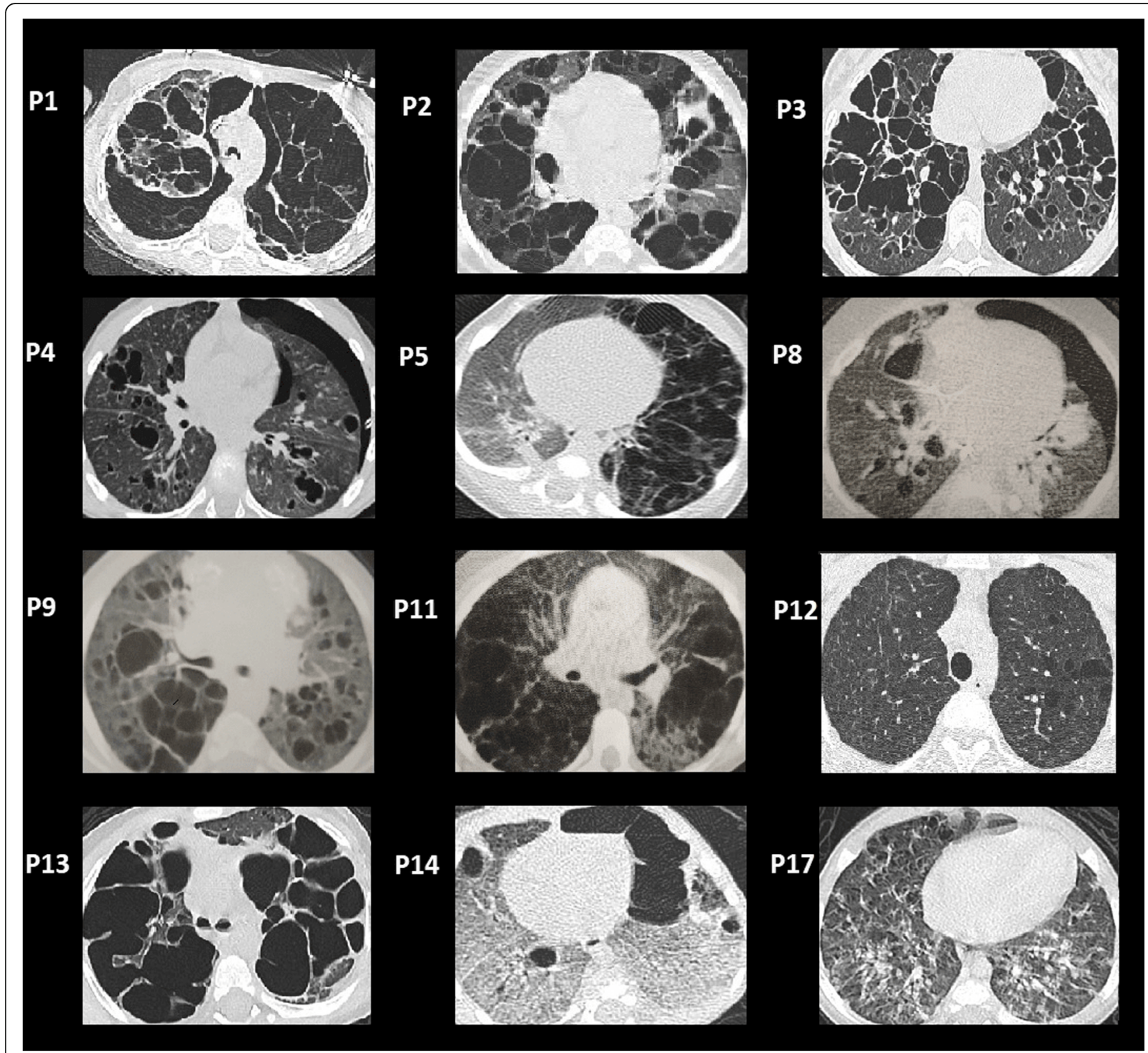

Fig. 1 Chest CT scan images (lung window). Initial images of PLCH for 12 of 17 patients. PLCH: Pulmonary Langerhans cell histiocytosis

\section{Characteristics of ICU hospitalization}

A total of 35 ICU hospitalizations were analysed, representing a median of 2 ICU hospitalizations per patient (range: 1 to 4, Fig. 2). The median time between the PLCH diagnosis and the first ICU admission was 9 days. The median ICU stay was 14 days (range: 2 to 151). For patients that required multiple ICU hospitalizations $(n=$ 12 ), the median interval between ICU hospitalizations was 17 days (range: 1 to 316 days).

Among the respiratory decompensations that led to ICU hospitalizations, 12 children experienced a complete pneumothorax (representing 22/35 (63\%) reported ICU hospitalizations). Among these, 5 patients experienced a bilateral pneumothorax. All 22 pneumothorax events were managed with chest tube drainage; $9 / 12$ patients
(75\%) also received pleurodesis (including thoracotomy pleurectomy surgery: $n=4$; talc or chemical pleurodesis: $n=4$; or a combined method: $n=1$ ). Only 2 children did not experience a pneumothorax relapse after pleurodesis; the other 7 children experienced pneumothorax recurrences and required several pleurodesis procedures (median: 2 pleurodeses per patient, range: 1 to 5 ).

In $8 / 35$ (23\%) ICU hospitalizations, the respiratory distress syndrome was associated with a diffuse micronodular lung infiltration in the context of MS LCH.

Finally, in 5/35 (14\%) ICU hospitalizations, the respiratory distress syndrome was associated with a severe cystic lung lesion, and among these, one patient underwent a left complete pneumonectomy 24 days after the $\mathrm{LCH}$ diagnosis. 


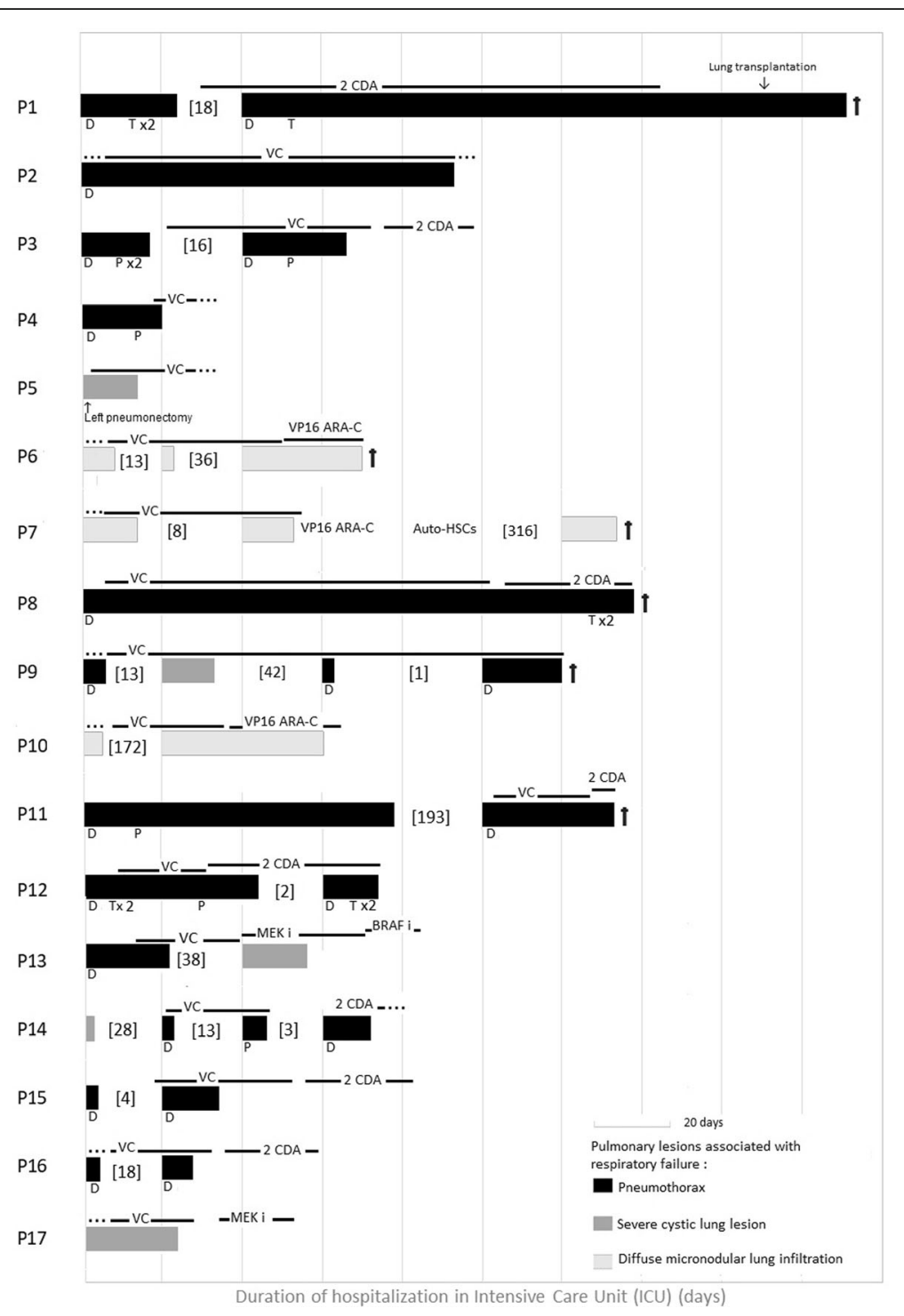

Fig. 2 Intensive care unit (ICU) hospitalizations and management for 17 patients with pulmonary Langerhans cell histiocytosis. Solid bars represent one ICU stay, and the length of stay is proportional to the scale bar (each section on the X-axis $=20$ days). Bracketed numbers are the number of days between ICU stays. $\square$ indicates death. Pulmonary lesions associated with respiratory failure are indicated with shading (black: pneumothorax; dark grey: severe cystic lung lesion without pneumothorax; light grey: diffuse micronodular lung infiltration). Anti-LCH treatments are specified above each ICU stay, and the treatment time is indicated with lines (VC: vinblastine corticosteroid; VP16 Ara-C: Etoposide-Cytarabine; 2CDA: Cladribine; Mek i: MEK inhibitor; BRAF i: BRAF inhibitor). Points before or following the lines indicate ongoing treatments for unspecified times. Pneumothorax treatments are indicated under each ICU stay (D: drainage, T: talcage, P: pleurectomy by thoracotomy)

In 9/35 (26\%) ICU hospitalizations, a viral respiratory infection (VRI) was identified at admission. These VRIs included respiratory syncytial virus (RSV), rhinovirus, human metapneumovirus, influenza A virus, and parainfluenza virus 3.

\section{Management during ICU hospitalization}

All patients required oxygen therapy during ICU hospitalization. Additionally, 10 patients (59\%) required invasive mechanical ventilation (IMV), and the median cumulative duration was 17.5 days per patient. One patient required a tracheotomy, due to prolonged IMV (48 days of IMV) without the possibility of extubation. One patient acquired an IMV-associated nosocomial pneumonia. In 3 ICU hospitalizations (diffuse micronodular lung infiltration: $n=1$; pneumothorax: $n=2$ ), noninvasive ventilation was administered without IMV.

The first-line LCH-specific therapies (Table 2) included the combined vinblastine corticosteroid (VC) therapy for 16 patients and 2-Chlorodeoxyadenosine (2CDA) therapy for one patient. Among the 16 patients that received $\mathrm{VC}$, only 3 cases showed evidence of a 
Table 2 Characteristics of PLCH and therapies at diagnosis and during follow-up

\begin{tabular}{|c|c|c|c|}
\hline Characteristic & At PLCH diagnosis $n=17$ & After the last ICU hospitalization $n=11^{\mathrm{a}}$ & At last visit $n=11^{\mathrm{a}}$ \\
\hline Median interval after the PLCH diagnosis & - & $\begin{array}{l}63 \text { days } \\
\text { (range: 4-966) }\end{array}$ & $\begin{array}{l}11.2 \text { years } \\
\text { (range: } 0.5-16)\end{array}$ \\
\hline \multicolumn{4}{|l|}{ Respiratory symptoms } \\
\hline No symptoms & $3(20)$ & $2(25)$ & $9(82)$ \\
\hline NYHA 2 & $2(13)$ & $5(38)$ & $2(18)$ \\
\hline \multicolumn{4}{|l|}{ NYHA 3} \\
\hline NYHA 4 & $12(71)$ & $4(36)$ & \\
\hline Oxygen requirement & $12(71)$ & $4(36)$ & 0 \\
\hline \multicolumn{4}{|l|}{ LCH therapy } \\
\hline VLB Steroid & $16(94)$ & $3(27)$ & \\
\hline VP16 ARA-C & & $1(9)$ & \\
\hline $2 \mathrm{CDA}$ & $1(7)$ & $5(45)$ & \\
\hline Targeted therapy & & $2(18)$ & $2(18)$ \\
\hline DAS Score, Median [min, max] & $5[3,23]$ & $3[1,3]$ & $1[1,1]$ \\
\hline CT Scores, & (11 evaluated cases) & (7 evaluated cases) & (7 cases evaluated) \\
\hline Cyst, median [min, max] & $12[0,24]$ & $10[0,21]$ & $10[0,18]$ \\
\hline Nodule, median [min, max] & $0[0,6]$ & $0[0,3]$ & $0[0,2]$ \\
\hline
\end{tabular}

Values are the number of patients (\%), unless indicated otherwise

-: not applicable

Abbreviations: DAS Disease Activity Score, CT computed tomography, ICU intensive care unit, LCH Langerhans cell histiocytosis, NYHA New York Heart Association, PLCH Pulmonary LCH, VLB vinblastine, VP16 Ara-C Etoposide-Cytarabine, 2CDA Cladribine

${ }^{a} 6$ patients died in the last ICU

response and remained alive with no $\mathrm{LCH}$ reactivation. The patient that received 2CDA did not respond; therefore, a lung transplantation was undertaken, and the patient died, following a solid organ transplant-associated acute graft-versus-host disease, as previously reported by Galambrun et al. [24] Among the 13 non-responders to $\mathrm{VC}$, one died after $\mathrm{VC}$ therapy without evidence of any response.

Seven patients were treated with $2 \mathrm{CDA}$ as a 2 nd line therapy. Of these, 5 responded without $\mathrm{LCH}$ reactivation, and 2 did not respond and died. Three patients received a combination of etoposide and cytarabine. Of these, 2 patients did not respond and subsequently died, and one showed a partial response ( 2 reactivations). Finally, 2 patients were treated with a targeted therapy (BRAF inhibitor: $n=1$; MEK inhibitor: $n=1$ ). Both showed responses without reactivation at a median of 6 months after ICU admission (Fig. 3).

\section{Outcome}

A total of 6 children (35\%) died. Median time to death after PLCH diagnosis was 6.9 months (range: 4.6 to 13.7 months). Estimated 5-year survival rate after PLCH diagnosis was $62.7 \%$ (95\%CI: $34.8-81.3 \%$; Fig. 4). Five patients died from respiratory failure during the ICU hospitalization (following repeated pneumothoraxes: $n=$ 3 ; diffuse micronodular lung infiltration in the context of MS: $n=2$ ) and one died from graft-versus-host disease after lung transplantation (Table 3) [24]. For $4 / 6$ children with a determined lung CT score, the median radiological score at the PLCH diagnosis was 16 for cysts and 0 for nodules but this score was not available for the 2 patients with diffuse micronodular lung infiltration in the context of MS disease.

The 11 surviving children had a median follow-up of 11.2 years after the last ICU (range: 0.4 to 15.7 years). Three children required prolonged supplemental oxygen after the ICU for a 1 month to 2.5 years period, but none remained under oxygen at last contact. Nine survivors (including one case that underwent a left complete pneumonectomy) were leading a normal life and practicing sports, despite imperfect lung function and radiological sequelae. Only 2 patients remained symptomatic, with NYHA II dyspnoea. Seven of the surviving patients had an imaging follow-up available. At the PLCH diagnosis, 7/11 patients with a determined lung CT score had median radiological scores of 12 for cysts and 2 for nodules. At the last visit, these patients had median scores at 10 for cysts and 0 for nodules.

\section{Discussion}

In this study, we described a cohort of 17 children with severe lung $\mathrm{LCH}$ registered in the last 30 years in the French $\mathrm{LCH}$ registry. This registry was based on the nationwide multicentric inclusion of patients treated within a longstanding, well-structured network of oncopaediatric and 


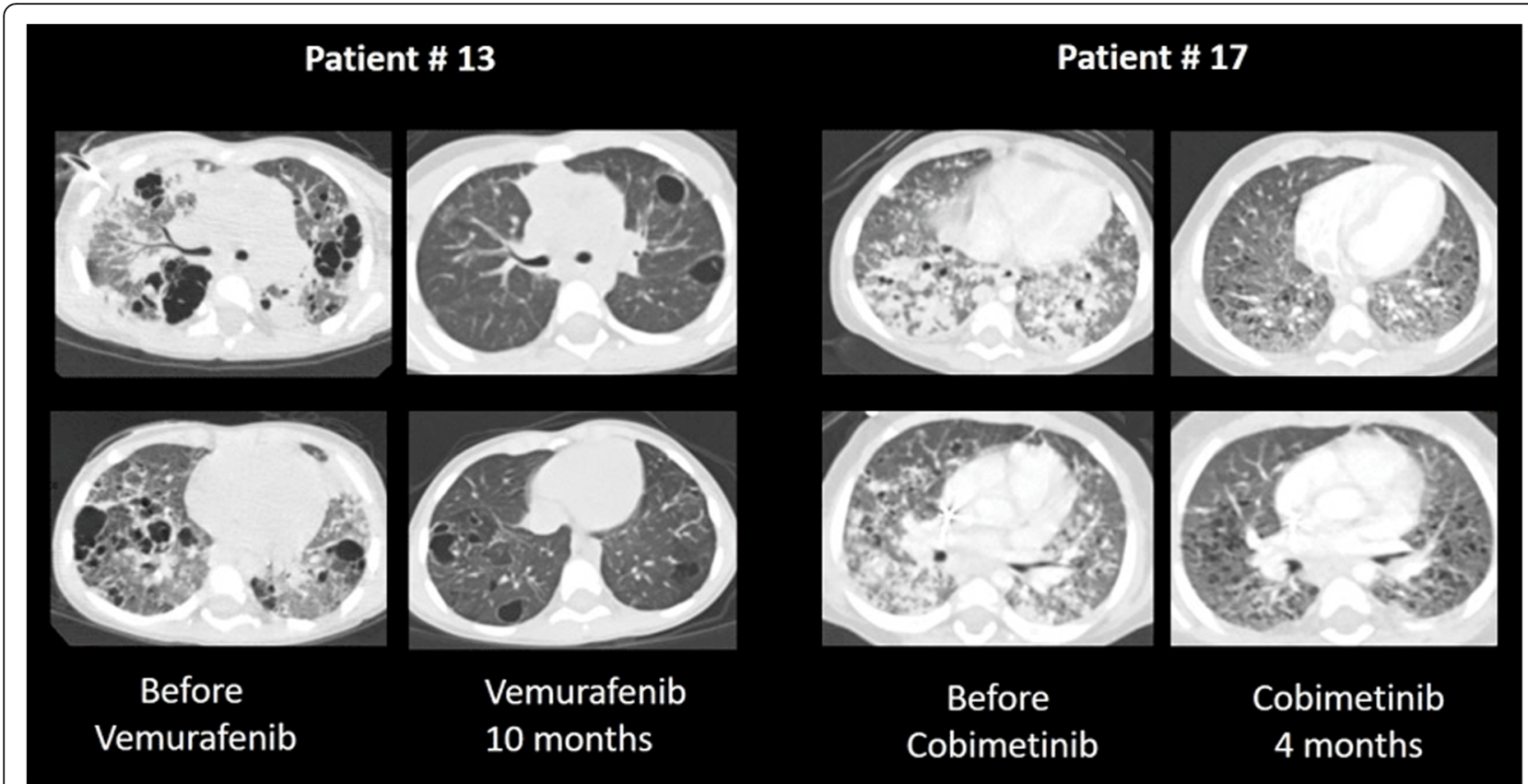

Fig. 3 Chest CT scan images (lung window) before and after initiation of target therapy. Images show lungs before and after the initiation of a BRAF-kinase inhibitor (Vemurafenib) and a MEK inhibitor (Cobimetinib)

pathologist practices $[4,13,32]$. Consequently, it is likely that nearly all children in France presenting LCH during the study period were reported in this registry. Accordingly, the presentation of severe lung LCH could be considered very rare; it represented $1 \%$ of all childhood $\mathrm{LCH}$ cases and $\sim 10 \%$ of all LCH cases with lung involvement in children $[4,32]$. In the literature, pulmonary involvement in children with LCH has been reported in many studies, but severe cases have been very rarely described $[5,7,14]$. For example, Ha et al. described 24 children with PLCH, but only 2 had respiratory complications [6]. To our knowledge, this study was the first to focus on severe childhood PLCH with a long follow-up (median followup for survivors: 11.2 years after ICU). Most of our

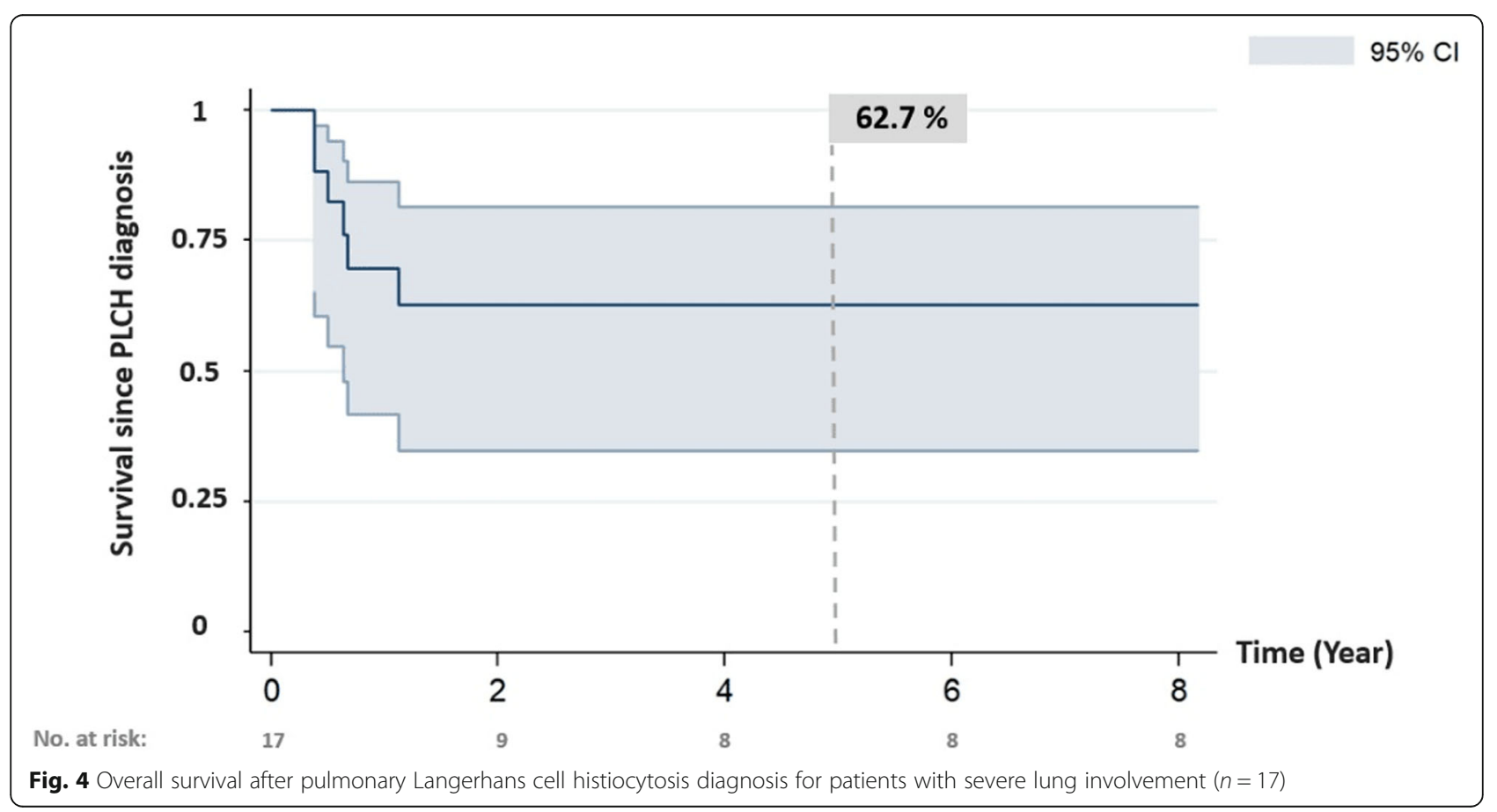


Table 3 Characteristics of children that died of PLCH and comparison with surviving patients

\begin{tabular}{|c|c|c|c|}
\hline Characteristics & Deceased patients, $\boldsymbol{n}=6$ & Surviving patients, $\boldsymbol{n}=11$ & $\boldsymbol{P}$ value \\
\hline Age at PLCH diagnosis, median [min, max] & 1.0 y $[0.2-5.0]$ & 1.4 y $[0.1-13.7]$ & 0.8 \\
\hline RO- $\mathrm{LCH}$ disease & 3 & 7 & 0.6 \\
\hline $\mathrm{RO}+\mathrm{LCH}$ disease & 3 & 4 & \\
\hline Maximal DAS Score, median [min, max] & $13.5[7,27]$ & $5[4,10]$ & 0.04 \\
\hline \multicolumn{4}{|l|}{ First-line LCH therapy } \\
\hline VLB Steroid & 5 & 11 & 0.4 \\
\hline $2 \mathrm{CDA}$ & 1 & 0 & \\
\hline \multicolumn{4}{|l|}{ Second-line LCH therapy } \\
\hline $2 \mathrm{CDA}$ & 2 & 5 & 0.4 \\
\hline VP16 ARA-C & 2 & 1 & \\
\hline Targeted therapy & 0 & 2 & \\
\hline CT Score at PLCH diagnosis & ( $n=4$ evaluated cases) & ( $n=9$ evaluated cases $)$ & \\
\hline Cyst, median [min, max] & $16[8,24]$ & $10[1,18]$ & 0.14 \\
\hline Nodule, median [min, max] & $0[0,0]$ & $3[0,9]$ & 0.08 \\
\hline$B R A F^{\vee 600 E}$ mutated $\mathrm{LCH}$ & $0 / 2$ investigated cases & $4 / 9$ investigated cases & 0.5 \\
\hline Time to death after PLCH diagnosis, median [min, max] & 6.9 months $[4.6,13.7]$ & & \\
\hline \multicolumn{4}{|l|}{ Cause of death } \\
\hline Repeated pneumothorax & 3 & - & \\
\hline Diffuse micronodular lung infiltration & 2 & & \\
\hline Post lung transplant & 1 & & \\
\hline
\end{tabular}

Values are the number of patients, unless indicated otherwise

Abbreviations: DAS Disease Activity Score, CT computed tomography, LCH Langerhans cell histiocytosis, PLCH Pulmonary LCH, RO Risk organs involved (+) or not involved (-), VLB vinblastine, VP16 Ara-C Etoposide-Cytarabine, 2CDA Cladribine

knowledge about PLCH is mainly based on adult pulmonology studies, because lung LCH involvement mostly affects young adults $[9,17]$. Several studies have shown that tobacco consumption directly affected adult PLCH; however, we lack explanations for the onset of PLCH in young children. Passive smoke exposure has not been identified as a risk factor for PLCH in children.

In this study, the children with severe lung disease were very young (median age at $\mathrm{LCH}$ diagnosis: 1.2 years), as previously reported [14, 33]. All but one displayed severe lung damage at the time of the LCH diagnosis. Most damage was represented by extended and probably insidious cystic lesions. The main cause of ICU hospitalizations was pneumothorax, but we also observed respiratory failure associated with severe cystic lung lesions (without pneumothorax) and diffuse micronodular lung infiltrations. Of note, $26 \%$ of ICU hospitalizations were associated with an identified VRI, probably representing a common cause of respiratory decompensation. Accordingly, we strongly recommend annual vaccinations against influenza. Moreover, RSV prophylaxis with palivizumab should be considered during the first year after a PLCH diagnosis, as previously proposed for other severe lung disorders in young children [34].
The 5-year survival rate was $62.7 \%$. This low survival rate testified to the severity of this rare $\mathrm{LCH}$ presentation, particularly during the critical period of the first year after PCLH diagnosis. Indeed, all deceased patients died within a median of 7 months (range: 4.6-13.7) after the PLCH diagnosis. For hospitalizations with pneumothorax, recurrences of pneumothorax were common, despite pleurodesis $[19,20,25,26]$. Optimal management for preventing pneumothorax recurrences has not been clearly established for children with $\mathrm{LCH}$. For adults, surgical pleurodesis might be indicated in cases of recurrence, but a pleurectomy is typically avoided for patients that might be candidates for lung transplantation [17]. However, recurrent pneumothorax, despite pleurodesis, remains an issue, and further studies are needed to determine the best management for reducing the risk of pneumothorax recurrence in PLCH $[11,35,36]$. A pneumonectomy might be considered when the damage is localized, as described for one patient in this study.

Our investigation of therapeutic efficacy in controlling $\mathrm{PLCH}$ showed that a minority of patients responded to $\mathrm{VC}(3 / 16)$, and 5 of 8 patients treated with 2CDA responded without reactivation. 
Conversely, none of the 3 patients treated with the etoposide-cytarabine combination (used in the 90s, but no longer recommended) survived without reactivation. Despite the low number of patients treated in each group, our findings highlighted the difficulty in managing LCH disease with severe lung involvement. In adults, $\mathrm{VC}$ is not indicated for treating $\mathrm{PLCH}$, due to the poor response rate, and 2CDA is indicated as the first-line therapy for PLCH, when systemic chemotherapy is required [37]. For children, VC therapy is suitable as a first-line treatment for all $\mathrm{LCH}$ involvements, including PLCH [30]. However, in our study, the $\mathrm{VC}$ response rate was low for children with severe $\mathrm{PLCH}$. 2CDA is an alternative option, but it might have adverse effects, such as a prolonged immunosuppression. Due to the small number of patients included in this study, it was difficult to draw conclusions about the optimal chemotherapy for treating PLCH. Notably, targeted therapies might also represent an interesting option. Two of our patients were treated with targeted therapy and showed continued clinical and radiological improvement, from the beginning of therapy, and both remain alive currently.

Molecular knowledge of histiocytosis has provided new avenues of potential progress in histiocytosis, particularly in terms of treatment [28]. In patients with $\mathrm{LCH}$ associated with $B R A F^{\mathrm{V} 600 \mathrm{E}}$ mutations (55\% of children with LCH [4]), a BRAF inhibitor showed efficient effects. The other mutations associated with $\mathrm{LCH}$ (MAP2K1, BRAFindel) were responsive to MEK inhibitors [28]. Thus, considering the severity of this $\mathrm{LCH}$ presentation, we believe that the use of targeted therapy would be justified, because it showed rapid efficacy in LCH $[29,38,39]$.

Our findings also justified the use of an adapted initial intensive management as our survivors experienced long-term, good quality of life and improved lung function, despite persistent radiological lung lesions (chronic cysts). No survivors developed late respiratory failure that required a lung transplantation [40].

\section{Conclusions}

We showed that, although the lung is no longer considered an $\mathrm{RO}$ in childhood $\mathrm{LCH}$, some severe lung presentations were associated with an adverse prognosis. These presentations represented a very tiny fraction of all lung involvement in $\mathrm{LCH}$, but their management remains highly challenging. Future studies should define optimal management approaches for pneumothorax complications and infectious prophylaxis, particularly during the first year after the PLCH diagnosis. Moreover, to optimize LCH therapy for these patients, future studies should evaluate using targeted therapies early in the development of severe PLCH in young children.

\section{Supplementary information}

Supplementary information accompanies this paper at https://doi.org/10. 1186/s13023-020-01495-5.

Additional file 1: Supplemental Table 1. Comparison of $\mathrm{PLCH}$ children with $(n=17)$ and without $(n=94)$ history of ICU admissions for respiratory failure. Data from the whole $\mathrm{LCH}$ cohort of children bellow 15 years of age at diagnosis $(n=1482)$ is also reported in order to give reference for the reader.

\section{Abbreviations}

2CDA: 2-Chlorodeoxyadenosine; CT: Computed Tomography scan;

DAS: Disease Activity Score; ICU: Intensive Care Unit; IMV: Invasive Mechanical Ventilation; LCH: Langerhans cell histiocytosis; Lung+ MS RO+ LCH: lung involvement with Risk Organ; Lung+ MS RO- LCH: lung involvement with other organ; Lung+ SS LCH: Isolated lung involvement; MS: Multi-system; NYHA: New York Heart Association; PLCH: Pulmonary LCH; RO + : Risk Organs involved; SS: Single-System; VC: Vinblastine Corticosteroid; VLB: vinblastine; VP16 Ara-C: Etoposide-Cytarabine; VRI: Viral Respiratory Infection

\section{Acknowledgments}

We would like to thank the patients and their families for their participation in this study. This study was based on research from the Centre de

Reference des Histiocytoses (www.histiocytose.org).

\section{Authors' contributions}

SL and SH conceptualized and designed the study, analyzed and interpreted the data, drafted the initial manuscript. All authors provided study materials and patients, contributed to the analysis and interpretation of data and critically reviewed the manuscript for important intellectual content; and all authors approved the final manuscript as submitted and agree to be accountable for all aspects of the work.

\section{Funding}

This study was supported by grants from the Société Française de lutte contre les Cancers de l'Enfant et de l'Adolescent; the Fédération Enfants et Santé; the Association Recherche et Maladie Hématologiques de I'Enfant; the Association Les 111 des Arts de Paris; and the Association la Petite Maison dans la Prairie. This project received ongoing support from the Association Histiocytose France. The French LCH registry was supported by a grant from InVS and INSERM for the rare disease registry, a grant from Roche, and funds from the Gardrat family.

Availability of data and materials

The datasets used and/or analysed during the current study are available from the corresponding author on reasonable request.

Ethics approval and consent to participate

All children were registered in French LCH registry. Patients in the registry had to fulfill LCH diagnostic criteria. Additionally their parents had to provide informed consent (Commission Nationale d'Informatique et des Libertés number in France: 909027) for a prospective follow-up. This procedure complied with the Declaration of Helsinki.

\section{Consent for publication}

N/A

\section{Competing interests}

The French $\mathrm{LCH}$ registry was supported by a grant from Roche. J.D. received travel support and honoraria from X4 Pharma. J.-F.E. received honoraria from Bristol-Myers Squibb, MSD Oncology, HalioDx, Pierre Fabre, and Amgen. We declare no other conflict of interest.

\section{Author details}

${ }^{1}$ French Reference Center for Langerhans Cell Histiocytosis, Trousseau Hospital, 26 avenue du Dr Netter, 75012 Paris, France. ${ }^{2}$ Department of 
Pediatric Hematology and Oncology, Hôpital de la Timone, Marseille, France. ${ }^{3}$ Department of Pediatric Hematology and Oncology, Centre Hospitalo-Universitaire de Bordeaux, Bordeaux, France. ${ }^{4}$ Department of Pediatric Hematology and Oncology, Brabois-Enfants Hospital, Centre Hospitalo-Universitaire de Nancy, Vandœuvre-lès-Nancy, France. ${ }^{5}$ Department of Paediatric Oncology, Institut d'Hémato-Oncologie Pediatrique, Lyon, France. ${ }^{6}$ Department of Pediatric Hematology and Oncology, Centre Hospitalo-Universitaire de Grenoble, La Tronche, France. ${ }^{7}$ Department of Pediatric Hematology and Oncology, Centre Hospitalo-Universitaire de Lille, Lille, France. ${ }^{8}$ Department of Pediatric Hematology and Oncology, Centre Hospitalo-Universitaire de Tours, Tours, France. ${ }^{9}$ Department of Pediatric Immunology, Hematology and Rheumatology, Necker Hospital, Assistance Publique-Hôpitaux de Paris, Paris, France. ${ }^{10}$ Institut Imagine, Sorbonne University, Paris, France. ${ }^{11}$ Department of Radiology, Trousseau Hospital, Assistance Publique-Hôpitaux de Paris, Paris, France. ${ }^{12}$ Department of Radiology, Centre Hospitalo-Universitaire de Bordeaux, Bordeaux, France. ${ }^{13}$ Intensive care unit, Necker Hospital, Assistance Publique-Hôpitaux de Paris, Paris, France. ${ }^{14}$ Intensive care unit, Trousseau Hospital, Assistance PubliqueHôpitaux de Paris, Paris, France. ${ }^{15}$ Intensive care unit, Lyon Hospices Civils, Lyon, France. ${ }^{16}$ Service de Pédiatrie générale, CHIC, Créteil, France. ${ }^{17}$ Service de Pneumologie, Arnaud de Villeneuve Hospital, Montpellier, France. ${ }^{18}$ Service de Pneumologie Centre de référence des histiocytoses Hôpital Saint Louis, Paris, France. ${ }^{19}$ Paris University, INSERM U976, Paris, France. ${ }^{20}$ EA4340, UVSQ, Paris-Saclay University, Boulogne-Billancourt, France.

${ }^{21}$ Départment of Pediatric Hematology and Oncology, Sorbonne University, Paris, France.

Received: 6 April 2020 Accepted: 5 August 2020

Published online: 09 September 2020

\section{References}

1. Guyot-Goubin A, Donadieu J, Barkaoui M, Bellec S, Thomas C, Clavel J. Descriptive epidemiology of childhood Langerhans cell histiocytosis in France, 2000-2004. Pediatr Blood Cancer. 2008;51:71-5.

2. Donadieu J, Guyot-Goubin A, Clavel J, Thomas C. Présentation clinique et épidémiologie de I'histiocytose langerhansienne chez l'enfant. Arch Pediatr. 2008;15:520-2

3. Berres M-L, Lim KPH, Peters T, Price J, Takizawa H, Salmon H, et al. BRAFV600E expression in precursor versus differentiated dendritic cells defines clinically distinct LCH risk groups. J Exp Med. 2015;212:281.

4. Héritier S, Emile J-F, Barkaoui M-A, Thomas C, Fraitag S, Boudjemaa S, et al. BRAF mutation correlates with high-risk Langerhans cell Histiocytosis and increased resistance to first-line therapy. J Clin Oncol. 2016;34:3023-30.

5. Ronceray L, Pötschger U, Janka G, Gadner H, Minkov M. Pulmonary Involvement in Pediatric-Onset Multisystem Langerhans Cell Histiocytosis: Effect on Course and Outcome. J Pediatrics. 2012;161:129-133.e3.

6. Ha SY, Helms P, Fletcher M, Broadbent V, Pritchard J. Lung involvement in Langerhans' cell Histiocytosis: prevalence, clinical features, and outcome. Pediatrics. 1992;89:466-9.

7. Braier J, Latella A, Balancini B, Castaños C, Rosso D, Chantada G, et al. Outcome in children with pulmonary Langerhans cell histiocytosis. Pediatr Blood Cancer. 2004;43:765-9.

8. Donadieu J, Héritier S. Histiocytose langerhansienne de l'enfant. Presse Med. 2017:46:85-95

9. Vassallo R, Harari S, Tazi A. Current understanding and management of pulmonary Langerhans cell histiocytosis. Thorax. 2017;72:937-45.

10. Tazi A, de Margerie C, Naccache JM, Fry S, Dominique S, Jouneau S, et al. The natural history of adult pulmonary Langerhans cell histiocytosis: a prospective multicentre study. Orphanet J Rare Dis. 2015;10:30.

11. Vassallo R, Ryu JH, Schroeder DR, Decker PA, Limper AH. Clinical outcomes of pulmonary Langerhans'-cell histiocytosis in adults. N Engl J Med. 2002; 346:484-90.

12. Seely JM, Salahudeen S, Cadaval-Goncalves AT, Jamieson DH, Dennie CJ, Matzinger FR, et al. Pulmonary Langerhans cell Histiocytosis: a comparative study of computed tomography in children and adults. J Thorac Imaging. 2012;27:65-70

13. Rigaud C, Barkaoui MA, Thomas C, Bertrand Y, Lambilliotte A, Miron J, et al. Langerhans cell histiocytosis: therapeutic strategy and outcome in a 30-year nationwide cohort of 1478 patients under 18 years of age. Br J Haematol. 2016;174:887-98.
14. Odame I, Li P, Lau L, Doda W, Noseworthy M, Babyn P, et al. Pulmonary Langerhans cell histiocytosis: a variable disease in childhood. Pediatr Blood Cancer. 2006;47:889-93.

15. Tazi A, Marc K, Dominique S, de Bazelaire C, Crestani B, Chinet T, et al. Serial computed tomography and lung function testing in pulmonary Langerhans' cell histiocytosis. Eur Respir J. 2012;40:905-12.

16. Kambouchner M, Emile J-F, Copin M-C, Coulomb-Lherminé A, Sabourin J-C, Della Valle $\mathrm{V}$, et al. Childhood pulmonary Langerhans cell histiocytosis: a comprehensive clinical-histopathological and BRAFV600E mutation study from the French national cohort. Hum Pathol. 2019;89:51-61.

17. Lorillon G, Tazi A. How I manage pulmonary Langerhans cell histiocytosis. Eur Respir Rev. 2017;26:170070.

18. Smets A, Mortelé K, Praeter GD, François O, Benoit Y, Kunnen M. Pulmonary and mediastinal lesions in children with Langerhans cell histiocytosis. Pediatr Radiol. 1997;27:873-6.

19. Yule SM, Hamilton JRL, Windebank KP. Recurrent pneumomediastinum and pneumothorax in Langerhans cell histiocytosis. Med Pediatr Oncol. 1997;29:139-42.

20. Braier J, Latella A, Balancini B, Castaños C, Goldberg J. Isolated pulmonary Langerhans cell histiocytosis presenting with recurrent pneumothorax. Pediatr Blood Cancer. 2007;48:241-4.

21. Epaud R, Ducou Le Pointe H, Fasola S, Ploussard S, Delestrain C, Sileo C, et al. Cladribine improves lung cysts and pulmonary function in a child with histiocytosis. Eur Respir J 2015:45:831-833.

22. Schulze J, Kitz R, Grüttner H-P, Schmidt H, Zielen S. Severe isolated pulmonary Langerhans cell histiocytosis in a 6-year-old girl. Eur J Pediatr. 2004;163:320-2.

23. Chatkin JM, Bastos JC, Stein RT, Gaiger AM. Sole pulmonary involvement by Langerhans' cell histiocytosis in a child. Eur Respir J. 1993;6:1226-8.

24. Galambrun C, Garaix F, Ughetto F, Picard C, Petit P, Bosdure E, et al. Cladribine-related immunosuppression may have fostered graft-versus-host disease after lung transplant for pulmonary Langerhans cell histiocytosis. Pediatr Blood Cancer. 2019;66:e27477.

25. Yokoyama S, Nakaoka T, Fukao D, Yokoyama K, Hara S, Hamahata K, et al. Pulmonary Langerhans cell histiocytosis with thyroid involvement manifesting as recurrent bilateral pneumothorax and tension bullae in a 3year-old child. Int J Surg Case Rep. 2019;60:239-43.

26. Alavi S, Ashena Z, Paydar A, Hemmati N. Langerhans cell histiocytosis manifesting as recurrent simultaneous bilateral spontaneous pneumothorax in early infancy. Pediatr Int. 2007;49:1020-2.

27. Oikonomou A, Prassopoulos P, Hytiroglou P, Kirvassilis FV, Tsanakas JN. Atypical CT findings of isolated pulmonary Langerhans cell Histiocytosis in a 4-year-old boy. J Thorac Imaging. 2007;22:176-9.

28. Héritier S, Emile J-F, Hélias-Rodzewicz Z, Donadieu J. Progress towards molecular-based management of childhood Langerhans cell histiocytosis. Arch Pediatr. 2019;26:301-7.

29. Donadieu J, Larabi IA, Tardieu M, Visser J, Hutter C, Sieni E, et al. Vemurafenib for refractory multisystem Langerhans cell Histiocytosis in children: an international observational study. J Clin Oncol. 2019;37:2857-65.

30. Haupt R, Minkov M, Astigarraga I, Schäfer E, Nanduri V, Jubran R, et al. Langerhans cell histiocytosis (LCH): guidelines for diagnosis, clinical work-up, and treatment for patients till the age of 18 years. Pediatr Blood Cancer. 2013;60:175-84.

31. Gadner H, Minkov M, Grois N, Pötschger U, Thiem E, Aricò M, et al. Therapy prolongation improves outcome in multisystem Langerhans cell histiocytosis. Blood. 2013;121:5006-14

32. Geissmann F, Thomas C, Emile JF, Micheau M, Canioni D, Cerf-Bensussan, et al. A multicentre retrospective survey of Langerhans cell histiocytosis: 348 cases observed between 1983 and 1993. The French Langerhans' cell histiocytosis study group. Arch Dis Child. 1996;75:17-24.

33. Ronceray L, Pötschger U, Janka G, Gadner H, Minkov M, German Society for Pediatric Hematology and Oncology, Langerhans Cell Histiocytosis Study Group. Pulmonary involvement in pediatric-onset multisystem Langerhans cell histiocytosis: effect on course and outcome. J Pediatr. 2012;161:129-33 e1-3.

34. Jeziorski E, Senechal B, Molina TJ, Devez F, Leruez-Ville M, Morand P, et al. Herpes-virus infection in patients with Langerhans cell histiocytosis: a casecontrolled sero-epidemiological study, and in situ analysis. PLoS One. 2008; 3:e3262.

35. Tazi A. Adult pulmonary Langerhans' cell histiocytosis. Eur Respir J. 2006;27:1272-85.

36. Le Guen P, Chevret S, Bugnet E, de Margerie-Mellon C, Lorillon G, SeguinGivelet A, et al. Management and outcomes of pneumothorax in adult patients with Langerhans cell Histiocytosis. Orphanet J Rare Dis. 2019;14:229. 
37. Weitzman S, Braier J, Donadieu J, Egeler RM, Grois N, Ladisch S, et al. 2'chlorodeoxyadenosine $(2-\mathrm{CdA})$ as salvage therapy for Langerhans cell histiocytosis (LCH). Results of the LCH-S-98 protocol of the histiocyte society. Pediatr Blood Cancer. 2009:53:1271-6.

38. Héritier $\mathrm{S}$, Jehanne $\mathrm{M}$, Leverger $\mathrm{G}$, Emile J-F, Alvarez J-C, Haroche J, et al. Vemurafenib use in an infant for high-risk Langerhans cell Histiocytosis. JAMA Oncol. 2015;1:836-8.

39. Lorillon G, Jouenne F, Baroudjian B, de Margerie-Mellon C, Vercellino L, Meignin $V$, et al. Response to Trametinib of a pulmonary Langerhans cell Histiocytosis harboring a MAP2K1 deletion. Am J Respir Crit Care Med. 2018, 198:675-8.

40. Dauriat G, Mal H, Thabut G, Mornex J-F, Bertocchi M, Tronc F, et al. Lung transplantation for pulmonary langerhans' cell histiocytosis: a multicenter analysis. Transplantation. 2006;81:746-50.

\section{Publisher's Note}

Springer Nature remains neutral with regard to jurisdictional claims in published maps and institutional affiliations.

- fast, convenient online submission

- thorough peer review by experienced researchers in your field

- rapid publication on acceptance

- support for research data, including large and complex data types

- gold Open Access which fosters wider collaboration and increased citations

- maximum visibility for your research: over $100 \mathrm{M}$ website views per year

At $\mathrm{BMC}$, research is always in progress. 